\title{
Long-term outcome of primary non-surgical root canal treatment
}

\author{
A. H. C. Lee • G. S. P. Cheung • M. C. M. Wong
}

Received: 26 July 2011 / Accepted: 12 December 2011 /Published online: 30 December 2011

(C) The Author(s) 2011. This article is published with open access at Springerlink.com

\begin{abstract}
Aim The aim of this study is to examine the survival distributions of primary root canal treatment using intervalcensored data and to assess the factors affecting the outcome of primary root canal treatment, in terms of periapical healing and tooth survival.

Materials and methods About one tenth of primary root canal treatment performed between January 1981 and December 1994 in a dental teaching hospital were systematically sampled for inclusion in this study. Information about the patients' personal particulars, medical history, preoperative status, treatment details, and previous review status of the treated teeth, were obtained from dental records. Patients were recalled for examination clinically and radiographically. Treatment outcomes were categorized according to the status for periapical healing and tooth survival. The event time was interval-censored and subjected to survival analysis using the Weibull accelerated failure time model.

Results A total of 889 teeth were suitable for analysis. Survival curves of both outcome measures (periapical healing and tooth survival) declined in a non-linear fashion with time. Median survival of the treated teeth was 119 months (periapical healing) and 252 months (tooth survival). Age, tooth type, pre-operative periapical status, occlusion, type of final restoration, and condition of the tooth/restoration margin were significant factors affecting both periapical healing and tooth survival. Apical extent and homogeneity of root
\end{abstract}

\footnotetext{
A. H. C. Lee · G. S. P. Cheung $(\bowtie) \cdot$ M. C. M. Wong Faculty of Dentistry, The University of Hong Kong, 3/F, Prince Philip Dental Hospital, 34 Hospital Road, Sai Ying Pun,

Hong Kong, HKSAR, China

e-mail: spcheung@hkucc.hku.hk
}

canal fillings had a significant impact towards periapical healing $(p<0.05)$, but not tooth survival.

Conclusion The longevity of treated teeth based on tooth survival was considerably greater than that of periapical healing. Both outcome measures were affected by a number of socio-demographic, pre-, intra-, and post-operative factors. Clinical relevance Root canal-treated teeth may continue to function for a considerable period of time even though there may be radiographic periapical lesion present. Decision for extraction may be due to reasons other than a failure of the periapical tissues to heal.

Keywords Endodontic treatment - Survival analysis . Longevity · Periapical healing · Extraction · Tooth loss

\section{Introduction}

In endodontics, the outcome of root canal treatment is an important event of interests. From a clinician's perspective, outcome in terms of periapical healing or post-treatment disease is probably the most important as the periapical status of a treated tooth determines whether the ultimate goal of endodontic treatment has been achieved or not [1]. On the other hand, a relatively new measure, known as tooth survival, is considered to be more patient-centered [2], and is more consistent with and comparable to that used in outcome studies of other treatment modalities, such as the implant-supported restorations [3, 4]. Presumably, prognosis of root canal-treated teeth measured by these two different but somehow overlapping treatment outcomes might be influenced by different sets of factors.

Weiger et al. [5] and Cheung [6] have commented that simple calculation of a percentage value for the healed or survival rate does not accurately reflect the prognosis of the 
root canal-treated teeth. Indeed, it only reflects a snap-shot experience at a certain point in time and can be misleading because it does not reflect the change in healing or survival pattern over a longer observation period [7]. Although an "adjusted rate" has been reported in an attempt to factor the observation time into the calculation (to produce a certain percentage of failure occurrence per year) to provide, hopefully, a more realistic estimation of the prognosis, this assumption of a constant rate of deterioration of treatment effect with time still hardly reflects the truth [5]. In order to gain a more complete picture of the longevity of a treatment modality over time, survival analysis is considered more appropriate [7].

Survival analysis is a statistical method employed for analyzing the time to an event occurrence, to compute the cumulative survival probability up to a certain time point [8]. In dentistry, an "event" can only be known to have occurred when a diagnosis is made at a dental visit. It follows the occurrence time of that event, typically, is less than or equal to the time when it is first observed. Therefore, the actual time of event falls between two review visits, hence a so-called interval-censored observation. An observation is said to be right-censored when the event has not occurred, but is unknown whether it will occur in the future $[8,9]$.

Patients who are regularly reviewed at frequent intervals would be suitable for survival analysis using the Life-Table approach. This is not always practicable, especially when one would like to keep the amount of radiation to the patient as low as possible. An alternative approach, the KaplanMeier (K-M) product-limit estimator that calculates the survival probability of the subject (or treatment) as a function of time, is a widely used statistical method for survival analysis in dentistry. Survival studies using Kaplan-Meier approach have been reported for primary non-surgical root canal treatment $[6,10,11]$ and for dental restorations. As the $\mathrm{K}-\mathrm{M}$ analysis requires the entry of an exact event date into the data set to produce a statistically meaningful result, the date of the last recall was often needed [8]. Another approach is by taking linear time estimates between two dental visits as the date of event [6]. However, these practices might lead to bias, error, and misleading result [9].

Over the years, a variety of methods for interval-censored data have been developed $[9,12,13]$. Such methods take into account the uncertainty as to the exact time when the event occurs within two consecutive reviews for a reliable and valid result [13]. Therefore, the aim of the present study was to examine the long-term outcome of primary non-surgical root canal treatment performed in a dental teaching hospital, with the specific objectives to evaluate the survival distributions of treatment outcome in terms of periapical healing and tooth survival with interval-censored data, and to identify factors that might affect these outcomes.

\section{Materials and methods}

\section{Sample}

A total sample of 999 teeth in 950 patients was obtained from a stratified random sample of patients treated in a dental teaching hospital. Some interim results have been reported previously $[6,10]$. Briefly, the sample population constituted about one tenth of all teeth that have been root canal treated between January 1981 and December 1994. The routine practice during that period included rubber dam isolation, manual preparation with stainless steel K-files using the Step-back or Step-down Technique, irrigation with a bland (sterile saline) or dilute $(0.5 \%)$ hypochlorite solution, and obturation using cold lateral compaction of gutta-percha with AH26 (Dentsply DeTrey, Konstanz, Germany) as sealer. The treatment, typically, were completed in two or more visits.

\section{Collection of data}

A data collection form was used to collate information about the patients' personal particulars and medical history, as well as the pre-operative status, treatment details, and documented review status of the treated teeth. Information was extracted from the treatment records for the clinical and radiographic findings.

When a sampled tooth has been retreated or extracted, the date of such treatment was recorded. Such information was obtained from the patient's record, if the treatment had been provided within the hospital, or by asking the patient over the phone for the relevant details. Attempt was made to contact the dental practitioner who provided the (remedial) treatment for the necessary information after obtaining consent from the patient for information release. Those who received pre-planned endodontic surgery as part of the initial endodontic treatment plan were excluded.

Of all samples, 277 teeth had been recorded as either retreated or extracted. In addition, 32 teeth had shown clinical signs or symptoms (as was recorded in the patient record), indicating post-treatment disease and loss of tooth survival (according to the definition by Friedman and Mor [2]). These 309 teeth were deemed to have "failed". The remaining 653 patients (690 teeth) were invited to return for a review appointment.

All patients who attended the review were examined by one operator $(\mathrm{AL})$ for the presence of any clinical signs or symptoms, including spontaneous pain, swelling, sinus tract, temperature sensitivity, increased mobility, and tenderness to palpation, percussion, or pressure. The integrity of the selected tooth and its restoration were examined for (recurrent) caries, fracture, and the presence of any marginal opening and occlusal interference. It was advised that ethics approval was not required because the clinical and radiographic procedures 
constituted a routine check-up and did not expose the patients to any unnecessary or additional risk(s). Patients who required further treatment were scheduled to be seen in another appointment.

For those patients who were unwilling or did not attend the recall, as well as those who were unable to be contacted (collectively called "discontinuers"), but the sampled teeth had been reviewed on at least one occasion after the primary treatment, the clinical and radiographic status were evaluated based on that (the most recent) review. To reduce the problem associated with too many early right-censored data [7], any discontinuer with the last review appointment that fell within 4 years after treatment but showing no adverse clinical signs or symptoms was excluded.

\section{Radiographic evaluation}

Paralleling periapical radiographs were taken using either one of the two methods: (1) conventional radiography-a size 2 dental X-ray film (Insight; Eastman Kodak, Rochester, NY, USA) with the use of a positioning device (XCP holder; Rinn, Elgin, IL, USA), and then developed in an automated processing machine (Velopex Intra XE; Medivance Instruments, London, UK); or (2) digital radiography - an intraoral sensor (Visualix HDI; Gendex, Milan, Italy) with a positioning device (Endo Bite Senso, Kerr; Sybron Dental Specialties, Bioggio, Switzerland) to produce a paralleling image.

Film-based radiographs were evaluated over a light box aided by a $2 \times$ magnifying viewer (X-ray Viewer; Directa AB, Upplands Väsby, Sweden) that would exclude extraneous light. Digital radiographic images were evaluated on a computer screen in a room with dimmed ambient lighting. Contrast and brightness of the digital images were adjusted, if required, to aid visualization of image details. All radiographs were coded and then evaluated by one operator (AL), with one fifth of the samples re-evaluated by the same operator after 4 weeks to check for intra-examiner variability. Any uncertain cases were evaluated by a second examiner independently; the examiners were calibrated beforehand. Then, any disagreement on the findings was discussed between the two examiners. If an agreement could not be reached, a third examiner was recruited to resolve the disagreement. Any disagreement cases that remained so were excluded from the study [14]. Radiographs were evaluated for the periapical status (see below), quality of the root canal filling (i.e., apical extent, presence of voids, profile in relation to original canal curvature), radiographic apical seal (apical to the post, if applicable), and presence of recurrent caries.

\section{Periapical status}

Given that all treatments had been provided for more than 4 years before this radiographic examination, the periapical status of the selected teeth was categorized, in accordance to the strict criteria [15], dichotomously into (1) healed-no periapical rarefaction, except widening of periodontal ligament space around an overextended filling, or (2) presence of periapical rarefaction.

The size of the periapical lesion, if present, was measured in two dimensions: vertical or length-wise $(L)$, and transverse or width $(W)$. The length-wise dimension $(L)$ was measured as the diameter of the radiolucent area along an imaginary axis that was an extension of the apical (curved) portion of the root. The transverse dimension $(W)$ was measured in a similar manner but along another imaginary axis drawn perpendicular to the length-wise diameter. In the presence of more than one focal area of rarefaction (as might be found with multi-rooted teeth), the largest radiolucent area was selected for measurement. Comparison of the size of radiolucent lesion would form the basis to determine if progressive disease was present for teeth with a pre-operative periapical radiolucency.

\section{Outcome measures}

When there was an absence of clinical signs, symptoms, or periapical radiolucency, the tooth was deemed to have achieved complete periapical healing. Teeth that had been extracted, retreated (surgically or non-surgically), or associated with any clinical signs, symptoms or periapical radiolucency were categorized as post-treatment disease.

Another outcome measure examined in this study was functional retention [2]; some refer to it as tooth survival [3, 16]. It was defined as the continuous function of the tooth in the mouth with absence of clinical symptoms, but regardless of their radiographic periapical status.

The recorded reasons for the failures (due to either posttreatment disease or loss of tooth survival) were noted. To eliminate any possible systemic influence or clustering, due to the inclusion of multiple teeth from one patient, a singlelevel modeling was used in this study. That is, only one tooth was randomly selected from each patient for entry into the statistical analysis if multiple teeth had previously been included in the initial sample.

\section{Statistical analysis}

The events of interest included the onset of post-treatment disease and the loss of tooth survival. For the latter, diagnosis might be easier, as the patient would be more likely to make a complaint when clinical symptoms have developed. On the other hand, post-treatment disease usually develops over time and may not be observed until a diagnosis is made on the basis of clinical and radiographic findings at a recall, or until acute symptoms or catastrophes such as tooth fracture set in $[6,10]$. The actual date of event (onset of posttreatment disease) would lie between the last known date 
when such condition was not observed (denoted as Dnodisease), and the date when it was first diagnosed (denoted as Ddisease). That is, the onset of post-treatment disease was interval-censored (Fig. 1). The same applied to the time measurement for tooth survival, which lied between the last known date that the tooth was still surviving (denoted as Dsurvival) and the date when the tooth was not (denoted as Dnosurvival) (Fig. 1). Note that Ddisease did not necessarily coincide with Dnosurvival, especially for asymptomatic teeth.

In this context, a review appointment served to update the status of the treated teeth, confirming Ddisease or Dnosurvival, if such event was noted, or resetting the period (Dnodisease or Dsurvival) up to this new date of examination. In the present analysis, date of obturation ( $D O$ in Fig. 1) was used as the origin of time measurement.

The survival probability of the treated teeth was computed for the two outcome measures, using the Weibull accelerated failure time (WAFT) model for interval-censored data [12]. One limitation of this model was that it could not analyze the data for an event (post-treatment disease or loss of tooth survival) observed at the first review, i.e., samples with data available only for Ddisease or Dnosurvival, but no information for Dnodisease or Dsurvival [17]. An assumption had to be made for these cases $(n=172$ and 73 for posttreatment disease and loss of tooth survival, respectively). From a clinician's point of view, it is reasonable to assume that the root canal-treated teeth would function for at least 2 weeks (being the typical time required for construction of the final restoration, especially for the sample population concerned in this study) before any problems may develop. Thus, the date of last review, Dnodisease or Dsurvival, was set to 2 weeks for those without any data for the first review.

Twenty-one factors, categorized as socio-demographic, pre-operative, intra-operative, or post-operative (Table 1), were examined statistically using the WAFT model individually at first. To examine any confounding or interdependence of factors, those factors with $p<0.2$ when tested individually (see $p$ values in Table 1) were re-entered into the overall analysis, until they were eliminated in a

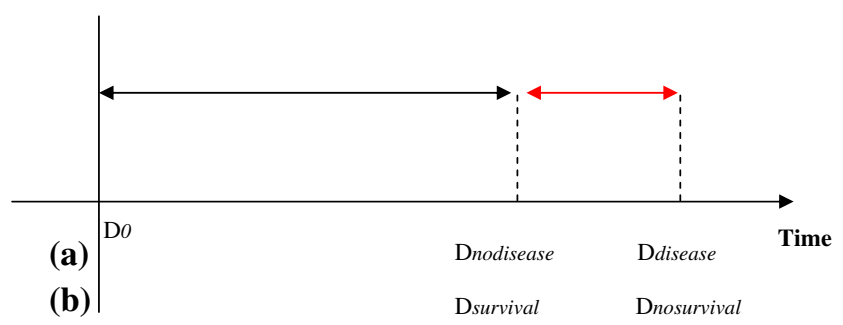

Fig. 1 Schematic diagrams illustrating the survival time of a tooth from date of obturation $(D 0)$ leading up to $(a)$ the development of posttreatment disease and $(b)$ loss of tooth survival. Note that the actual date of post-treatment disease and loss of tooth survival should lie between (a) Dnodisease-Ddisease and (b) Dsurvival-Dnosurvival backward stepwise method. Those factors that remained $(p<0.05)$ after the stepwise analysis formed the basis for calculating the hazard ratio (that is, the relative risk of developing an adverse reaction, compared with the reference group that was assigned a value of 1) and the $95 \%$ confidence intervals. All analysis was performed using PROC LIFEREG in the software SAS/STAT 9.2 (SAS Institute Inc. 2008, Cary, NC, USA).

\section{Results}

Of the 999 teeth in 950 patients, 110 teeth in 59 patients were excluded from this study due to various reasons (Table 2). The final sample for analysis involved 889 teeth from 889 patients.

The survival curves of both outcome measures declined in a non-linear fashion, consistently showing an initial rapid drop up to about 40 months which then slowed down with longer observation time (Fig. 2). The cumulative survival computed for periapical healing and tooth survival after 25 years was 0.29 and 0.46 , respectively (Fig. 2). That is, complete periapical healing was expected in $29 \%$ of root canal-treated teeth, and that $46 \%$ of all treated teeth would still be present in the mouth some 25 years after treatment. The median time for the onset of post-treatment disease was about 119 months, and for loss of tooth survival was approximately 252 months.

\section{Reasons for failure}

The reasons for failure due to either post-treatment disease or loss of tooth survival for short- ( $<40$ months) versus longterm ( $\geq 40$ months) observations are summarized in Table 3 . Presence of persistent or progressive apical periodontitis was the most prevalent reason of adverse outcomes. At the end of the study, $26.5 \%$ of teeth $(n=236)$ were recorded as extracted with known reasons. Of these, almost one third $(n=74)$ were carried out within the first 40 months after primary treatment. Nearly half of all the extraction $(n=116)$ was due to fracture of the crown or root.

Factors affecting outcome

Of the 21 factors examined, 19 were included for further analysis as they were found to have $p<0.2$ with either one or both of the outcome measures when tested individually (Table 1); only "pre-operative (clinical) signs or symptoms" and "acute flare-up during treatment" were eliminated. After backward stepwise examination, nine factors were found to be significant in their effect on either post-treatment disease or tooth survival in the final model (Table 4).

Factors that showed a positive favorable influence (i.e., hazard ratio less than 1; see Table 4) on periapical healing 
Table 1 Factors examined in this study $(N=889)$

\begin{tabular}{|c|c|c|c|c|c|}
\hline \multirow[t]{2}{*}{ Category } & \multirow[t]{2}{*}{ Covariables } & \multirow[t]{2}{*}{ Subgroups } & \multirow[t]{2}{*}{$N(\%)$} & \multicolumn{2}{|c|}{$\begin{array}{l}p \text { value from } \\
\text { individual test } \\
\text { on covariable }\end{array}$} \\
\hline & & & & $\begin{array}{l}\text { Healing } \\
\text { outcome }\end{array}$ & $\begin{array}{l}\text { Tooth } \\
\text { survival }\end{array}$ \\
\hline \multirow[t]{5}{*}{ Socio-economic } & \multirow[t]{3}{*}{ Age } & Below 25 years & $247(27.8)$ & \multirow[t]{3}{*}{$<0.001$} & \multirow[t]{3}{*}{$<0.001$} \\
\hline & & $25-50$ years & $444(50.0)$ & & \\
\hline & & Above 50 years & $198(22.2)$ & & \\
\hline & \multirow[t]{2}{*}{ Gender } & Male & $358(40.3)$ & \multirow[t]{2}{*}{0.003} & \multirow[t]{2}{*}{0.032} \\
\hline & & Female & $531(59.7)$ & & \\
\hline \multirow[t]{14}{*}{ Pre-operative } & \multirow[t]{2}{*}{ General health $(N=863$; missing 26$)$} & Healthy & $580(67.2)$ & \multirow[t]{2}{*}{0.428} & \multirow[t]{2}{*}{0.027} \\
\hline & & Not healthy & $283(32.8)$ & & \\
\hline & \multirow[t]{2}{*}{ Tooth location } & Maxilla & $512(57.6)$ & \multirow[t]{2}{*}{0.026} & \multirow[t]{2}{*}{0.089} \\
\hline & & Mandible & $377(42.4)$ & & \\
\hline & \multirow[t]{3}{*}{ Tooth type } & Anteriors & $336(37.8)$ & \multirow[t]{3}{*}{$<0.001$} & \multirow[t]{3}{*}{0.005} \\
\hline & & Premolars & $268(30.1)$ & & \\
\hline & & Molars & $285(32.1)$ & & \\
\hline & \multirow[t]{2}{*}{ Pre-operative signs or symptoms } & Absent & $401(45.1)$ & \multirow[t]{2}{*}{0.248} & 0.653 \\
\hline & & Present & $488(54.9)$ & & \\
\hline & Pre-operative pulpal status & Non-vital & $548(65.6)$ & 0.010 & 0.026 \\
\hline & & Vital & $288(34.4)$ & & \\
\hline & Pre-operative periapical status & No radiolucency & $516(58.0)$ & $<0.001$ & 0.002 \\
\hline & & $\leq 5 \mathrm{~mm}$ & $266(29.9)$ & & \\
\hline & & $>5 \mathrm{~mm}$ & $107(12.1)$ & & \\
\hline Intra-operative & Operator status & Undergraduate students & $629(70.8)$ & 0.029 & 0.054 \\
\hline & & Qualified dentists & $260(29.2)$ & & \\
\hline & Number of visits & 1 visit & $27(3.0)$ & $<0.001$ & $<0.001$ \\
\hline & $(N=888 ;$ missing 1$)$ & 2 visits & $301(33.9)$ & & \\
\hline & & 3 visits & $301(33.9)$ & & \\
\hline & & $\geq 4$ visits & $259(29.2)$ & & \\
\hline & Acute flare-up during & Absent & $792(93.6)$ & 0.892 & 0.490 \\
\hline & treatment $(N=846$; missing 43$)$ & Present & $54(6.4)$ & & \\
\hline & Extent of root filling $(N=870 ;$ missing 19$)$ & Flush $(0-2 \mathrm{~mm})$ & $675(77.6)$ & $<0.001$ & $<0.001$ \\
\hline & & Short $(>2 \mathrm{~mm})$ & $107(12.3)$ & & \\
\hline & & Overextension & $88(10.1)$ & & \\
\hline & Extrusion of root filling; including & Absent & $721(84.3)$ & $<0.001$ & 0.006 \\
\hline & sealer $(N=855$; missing 34$)$ & Present & $134(15.7)$ & & \\
\hline & Homogeneity of root filling & No apparent voids & $432(48.9)$ & $<0.001$ & 0.009 \\
\hline & $(N=883 ;$ missing 1$)$ & Voids in apical third & $252(28.5)$ & & \\
\hline & & Voids in middle or coronal third & $199(22.6)$ & & \\
\hline & Root filling profile & Follow original canal form & $721(81.7)$ & $<0.001$ & 0.101 \\
\hline & $(N=882 ;$ missing 7$)$ & $\begin{array}{l}\text { Sign(s) of ledging, transportation, } \\
\text { deviation, broken instrument, } \\
\text { or perforation }\end{array}$ & $161(18.3)$ & & \\
\hline Post-operative & Function $(N=875$; missing 14$)$ & Presence of both proximal contacts & $576(65.8)$ & 0.003 & $<0.001$ \\
\hline & & Presence of $\leq 1$ proximal contact & $128(14.6)$ & & \\
\hline & & $\begin{array}{l}\text { Cantilever/fixed-fixed/fixed- } \\
\text { movable bridge abutment }\end{array}$ & $68(7.8)$ & & \\
\hline & & Denture/overdenture abutment & $103(11.8)$ & & \\
\hline & Occlusion $(N=860$; missing 29$)$ & No opposing teeth, or opposing denture & $76(8.9)$ & 0.112 & 0.017 \\
\hline & & Opposing natural teeth & $733(85.2)$ & & \\
\hline
\end{tabular}


Table 1 (continued)

\begin{tabular}{|c|c|c|c|c|c|}
\hline \multirow[t]{2}{*}{ Category } & \multirow[t]{2}{*}{ Covariables } & \multirow[t]{2}{*}{ Subgroups } & \multirow[t]{2}{*}{$N(\%)$} & \multicolumn{2}{|c|}{$\begin{array}{l}p \text { value from } \\
\text { individual test } \\
\text { on covariable }\end{array}$} \\
\hline & & & & $\begin{array}{l}\text { Healing } \\
\text { outcome }\end{array}$ & $\begin{array}{l}\text { Tooth } \\
\text { survival }\end{array}$ \\
\hline & \multirow{3}{*}{ Post $(N=885 ;$ missing 4$)$} & Opposing fixed prosthesis & $51(5.9)$ & & \\
\hline & & Absent & $342(38.6)$ & \multirow[t]{2}{*}{$<0.001$} & \multirow[t]{2}{*}{$<0.001$} \\
\hline & & Present & $543(61.4)$ & & \\
\hline & \multirow{4}{*}{$\begin{array}{l}\text { Type of final restoration } \\
(N=831 ; \text { missing } 58)\end{array}$} & Amalgam & $189(22.7)$ & \multirow[t]{4}{*}{$<0.001$} & \multirow[t]{4}{*}{$<0.001$} \\
\hline & & Composite resin or GIC & $151(18.2)$ & & \\
\hline & & Indirect cuspal coverage restoration & $476(57.3)$ & & \\
\hline & & Others & $15(1.8)$ & & \\
\hline & \multirow{3}{*}{$\begin{array}{l}\text { Time to the placement of final restoration } \\
(N=700 ; \text { missing } 189)\end{array}$} & $\leq 2$ months & $270(38.6)$ & \multirow[t]{3}{*}{0.002} & \multirow[t]{3}{*}{$<0.001$} \\
\hline & & $>2-10$ months & $284(40.6)$ & & \\
\hline & & $>10$ months & $146(20.8)$ & & \\
\hline & \multirow[t]{2}{*}{ Condition of tooth/restoration margin } & Satisfactory & $679(76.4)$ & \multirow[t]{2}{*}{$<0.001$} & \multirow[t]{2}{*}{$<0.001$} \\
\hline & & Unsatisfactory & $210(23.6)$ & & \\
\hline
\end{tabular}

Missing values referred to those cases where the relevant information could not be identified in the patient records. Unhealthy included any known systemic diseases, immunosuppressive medication, or history of radiotherapy in the head and neck regions. Unsatisfactory tooth/restoration margin included the presence of recurrent caries, fracture, and/or marginal opening

included patient's age (50 years old or younger; $p<0.001)$, anterior teeth and premolars $(p=0.007)$, absence of preoperative periapical lesion $(p<0.001)$, tooth without any opposing or with opposing denture teeth $(p=0.028)$, root canal filling that appeared "flush" (0-2 mm) with the radiographic apex $(p=0.041)$, homogenously filled root with no radiographic void $(p=0.008)$, and those restored with a cuspal coverage restoration $(p<0.001)$ and with satisfactory tooth/restoration margin $(p<0.001)$.
A slightly different set of factors were found to affect tooth survival. Patient aged 50 years old or younger $(p<0.001)$, premolars $(p<0.001)$, absence of pre-operative periapical lesion $(p=0.003)$, tooth opposing a fixed prosthesis $(p=0.004)$, treatment completed in two visits (compared with that completed in four or more visits; $p=0.036)$, and tooth with a cuspal coverage restoration $(p<0.001)$ and with satisfactory tooth/restoration margin $(p<0.001)$ were found to enjoy a greater longevity, with significantly lower hazard
Table 2 Number of cases and reasons for exclusion from statistical analysis

\begin{tabular}{|c|c|c|}
\hline Reasons for exclusion & $\begin{array}{l}\text { No. of } \\
\text { teeth }\end{array}$ & Remarks \\
\hline $\begin{array}{l}\text { Mismatch of information with } \\
\text { patients' records }\end{array}$ & 7 & Entry errors in the original patient records \\
\hline $\begin{array}{l}\text { Periapical surgery pre-planned } \\
\text { as part of root canal treatment }\end{array}$ & 6 & \\
\hline Patient never returned for any review & 9 & \\
\hline $\begin{array}{l}\text { Retreatment cases, instead of } \\
\text { primary root canal treatment }\end{array}$ & 4 & Entry errors \\
\hline Right censoring $<4$ years & 31 & $\begin{array}{l}\text { Last available review date }<4 \text { years without any } \\
\text { observation of post-treatment disease or loss } \\
\text { of tooth survival; and patient never returned again }\end{array}$ \\
\hline Multiple teeth treated for a patient & 49 & $\begin{array}{l}\text { Only one tooth, randomly selected, was included for } \\
\text { each patient }\end{array}$ \\
\hline $\begin{array}{l}\text { Incomplete review information, } \\
\text { including uncertain healing }\end{array}$ & 2 & \\
\hline $\begin{array}{l}\text { Teeth survived for less than } \\
2 \text { weeks after root canal treatment }\end{array}$ & 2 & $\begin{array}{l}\text { Observation of post-treatment disease or loss of tooth } \\
\text { survival within } 2 \text { weeks }\end{array}$ \\
\hline $\begin{array}{l}\text { Total number of teeth excluded } \\
\text { (initial sample }=999 \text { ) }\end{array}$ & 110 & A total of 889 teeth were suitable for analysis \\
\hline
\end{tabular}


Fig. 2 Weibull survival curves for periapical healing and tooth survival outcome

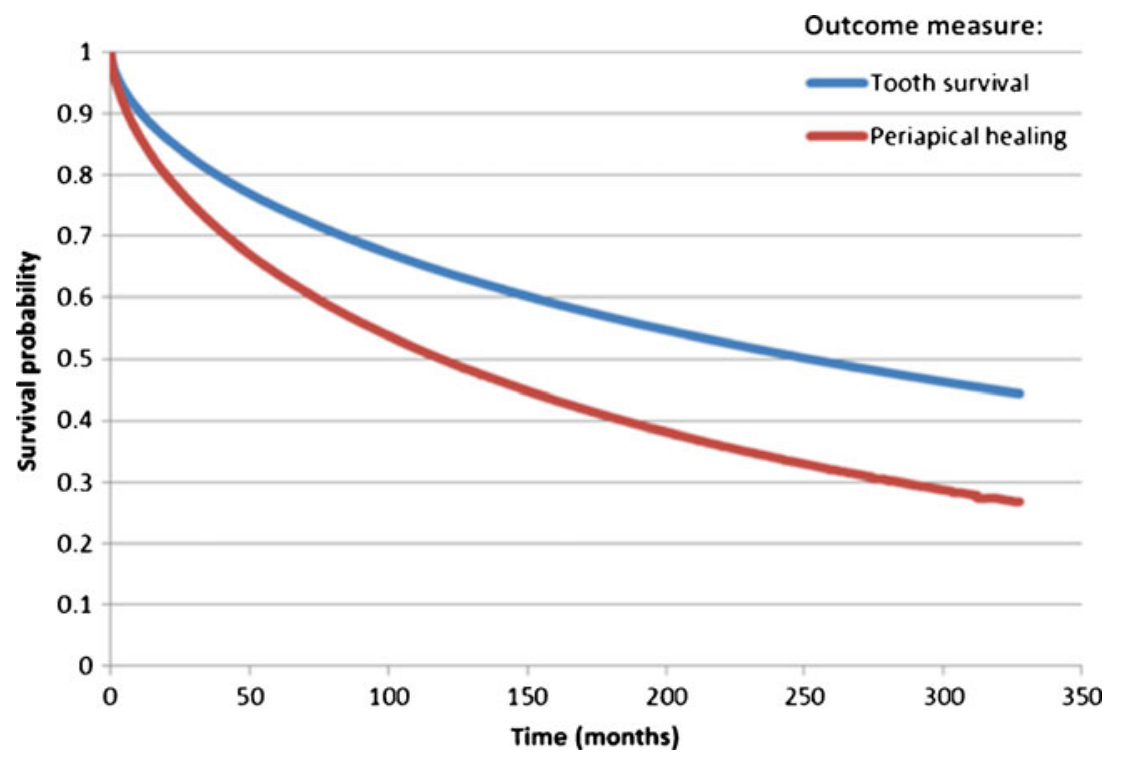

ratios compared to their respective reference subgroups (Table 4).

\section{Discussion}

\section{Methodology}

This study has the inherent limitations of any cohort clinical study. That is, the number of dropouts tends to increase with an extended observation period. A high dropout rate would jeopardize the precision of survival estimates from the analysis [18]. Fortunately, the present WAFT model takes into account not only those complete (interval-censored) but also incomplete (right-censored) observations, which should improve the reliability of the survival estimates. Information was extracted from the clinical documentation for the patients over the years. In the case when some entries were unavailable (e.g., due to patient not returning to the hospital for further treatment or review), retrospective information provided by the patient over the phone would become the only source of data. Such self-reported data could be subjected to prevarication, especially for the date of such events as retreatment, extraction, or incidence of pain.

Another limitation of the present study is related to the use of radiographs, as they only represented a twodimensional image of the three-dimensional structures of the jaw [19]. It is commonly accepted that lesions limited to the cancellous bone are almost impossible to detect with conventional radiographic technique [20], although other studies showed the opposite $[21,22]$. Cone-beam computerized tomography is a relatively new technique that produces a three-dimensional image of the bony structures and might be a useful tool to detect periapical lesions and for assessing endodontic healing outcome in the future [23].

Table 3 Summary of reasons for failure due to either post-treatment disease or loss of tooth survival for short- $(<40$ months $)$ vs. long-term ( $\geq 40$ months) observations

\begin{tabular}{|c|c|c|c|c|}
\hline Outcome measure & Reasons & $\leq 40$ months & $\geq 40$ months & Total ( $\%$ of total 889 cases $)$ \\
\hline \multirow[t]{3}{*}{ Post-treatment disease (clinical plus radiographic) } & Periapical periodontitis & 180 & 466 & $646(72.2)$ \\
\hline & Emerging & 38 & 98 & $136(15.3)$ \\
\hline & Persistent or progressive & 142 & 368 & $510(57.4)$ \\
\hline \multirow[t]{7}{*}{ Loss of tooth survival } & Clinical signs and symptoms & 85 & 170 & $255(28.7)$ \\
\hline & Extraction & 74 & 162 & $236^{\mathrm{a}}(26.5)$ \\
\hline & Failed RCT & 19 & 19 & $38(4.3)$ \\
\hline & Fractures-root & 26 & 54 & $80(9.0)$ \\
\hline & Fractures - crown & 9 & 27 & $36(4.0)$ \\
\hline & Periodontal reasons & 10 & 19 & $29(3.3)$ \\
\hline & Others & 10 & 43 & $53(6.0)$ \\
\hline
\end{tabular}

\footnotetext{
${ }^{\mathrm{a}}$ Total number of teeth extracted was actually 255 (same as those that developed signs and symptoms). Of these, the date or reason for extraction was unavailable for 19 teeth; thus, only 236 extracted teeth were listed here
} 
Table 4 Factors found to be significant $(p<0.05)$ after backward stepwise analysis using the Weibull accelerated failure time model for periapical healing and tooth survival outcome

\begin{tabular}{|c|c|c|c|c|}
\hline \multirow[t]{2}{*}{ Factors } & \multicolumn{2}{|l|}{ Periapical healing } & \multicolumn{2}{|l|}{ Tooth survival } \\
\hline & Hazard ratio $^{\mathrm{a}}(95 \% \mathrm{CI})$ & $p$ value & Hazard ratio $^{\mathrm{a}}(95 \% \mathrm{CI})$ & $p$ value \\
\hline Age & & $<0.001$ & & $<0.001$ \\
\hline$<25$ years & $0.48(0.36,0.64)$ & & $0.39(0.27,0.55)$ & \\
\hline $25-50$ years & $0.64(0.50,0.82)$ & & $0.60(0.45,0.79)$ & \\
\hline$>50$ years & 1 & & 1 & \\
\hline Tooth type & & 0.007 & & $<0.001$ \\
\hline Anteriors & $0.71(0.53,0.95)$ & & $0.72(0.52,1.00)$ & \\
\hline Premolars & $0.66(0.50,0.86)$ & & $0.52(0.38,0.71)$ & \\
\hline Molars & 1 & & 1 & \\
\hline Pre-operative periapical status & & $<0.001$ & & 0.003 \\
\hline No lesion & $0.60(0.44,0.80)$ & & $0.63(0.44,0.89)$ & \\
\hline$\leq 5 \mathrm{~mm}$ & $0.84(0.61,1.14)$ & & $0.92(0.64,1.33)$ & \\
\hline$>5 \mathrm{~mm}$ & 1 & & 1 & \\
\hline Occlusion & & 0.028 & & 0.004 \\
\hline Non-opposing/opposing denture & 1 & & $1.66(0.82,3.33)$ & \\
\hline Opposing (natural teeth) & $1.61(1.12,2.32)$ & & $2.45(1.35,4.46)$ & \\
\hline Opposing (fixed prosthesis) & $1.30(0.77,2.19)$ & & 1 & \\
\hline Extent of root filling & & 0.041 & Not significant & NS \\
\hline Flush & $0.68(0.49,0.93)$ & & & \\
\hline Short & $0.84(0.57,1.23)$ & & & \\
\hline Overextended & 1 & & & \\
\hline Homogeneity of root filling & & 0.008 & Not significant & NS \\
\hline No voids, apparently & $0.76(0.59,0.98)$ & & & \\
\hline Homogenous & & & & \\
\hline Voids in apical third & $1.08(0.83,1.41)$ & & & \\
\hline Voids in middle/coronal third & 1 & & & \\
\hline Number of visits & Not significant & NS & & 0.036 \\
\hline 1 & & & $0.63(0.29,1.39)$ & \\
\hline 2 & & & $0.64(0.47,0.88)$ & \\
\hline 3 & & & $0.86(0.65,1.14)$ & \\
\hline 4 or more & & & 1 & \\
\hline Type of final restoration & & $<0.001$ & & $<0.001$ \\
\hline Amalgam & 1 & & 1 & \\
\hline Composite/GIC & $0.69(0.49,0.97)$ & & $0.70(0.47,, 1.03)$ & \\
\hline Indirect cuspal coverage & $0.51(0.40,0.65)$ & & $0.41(0.31,0.55)$ & \\
\hline Restoration & & & & \\
\hline Others & $1.73(0.85,3.52)$ & & $1.36(0.65,2.84)$ & \\
\hline Condition of the tooth/restoration margin & & $<0.001$ & & $<0.001$ \\
\hline Satisfactory & $0.63(0.51,0.79)$ & & $0.47(0.36,0.60)$ & \\
\hline Unsatisfactory & 1 & & 1 & \\
\hline
\end{tabular}

${ }^{\text {a }}$ Hazard ratio is the relative risk of having adverse reaction when compared with the reference group (which was assigned an value of 1). A hazard ratio greater than 1 indicates a higher risk of developing an adverse outcome (i.e., failure to achieve periapical healing, or loss of tooth survival) relative to the reference group

With the use of the WAFT model for interval-censored data $[12,13]$, one could expect to get a reliable and valid result. The problem of early right-censored data (i.e., last review being made shortly after the treatment with no adverse outcome but then patient never returned again), which tends to introduce more errors in survival analysis [7], was 
mostly eliminated in this study because those right-censored observations with less than 4 years of review were excluded. This is in line with the recommendation that root canal treatment (with uncertain outcome) should be reviewed for 4 years before a definite decision of failure (to heal) is made [1]. Inevitably, this would also exclude some cases that might have exhibited signs of favorable periapical healing before that period but were not reviewed further. Thus, there was a possibility of underestimating the survival outcomes for the first 4 years of observation. Fortunately, only a small number of samples $(n=31$ or $3.1 \%$ of total sample) were excluded from the initial sample due to such early rightcensoring (Table 2). On the other hand, it was not uncommon to find cases that were condemned as "failed" and retreated (surgical or non-surgically) within the first 4 years after treatment, often without obvious symptoms or signs of disease progression documented. This might truly have resulted in the "unfair" inclusion of the failure cases for both outcome measures especially in the early posttreatment periods.

In an epidemiologic survey of (the insurance records of) over 1.4 million teeth, Salehrabi and Rotstein [24] reported that $97 \%$ of teeth survived some 8 years after primary nonsurgical root canal treatment. Similar studies by Lazarski et al. [25] and Chen et al. [26] also reported high survival rates of $94 \%$ (3.5 years of observation) and 93\% (5 years), respectively. However, these studies were done on dental insurance records of patients without reference to the clinical conditions of the tooth, especially for the presence of any symptoms on the date of study. Our results suggested a somewhat lower tooth survival rate at those corresponding periods of observation (Fig. 2). The difference may be due to a number of reasons: (1) criteria for failure - our study here also included clinical signs or symptoms as an unfavorable outcome for tooth survival; (2) sample selectionpatients in the above epidemiologic studies were recruited from population enrolled in dental insurance plans, who might possess a different attitude and awareness towards dental health and tooth retention from the sample (mostly walk-in patients on a need basis) in the present study; and (3) treatment providers - treatment for patients in the epidemiologic studies were provided by either qualified dentists or endodontists, as opposed to that by undergraduate students in the majority of cases here.

Factors affecting the outcome of primary root canal treatment

While many studies failed to find any association between patient age and periapical healing after primary root canal treatment [27-29], we found that patients above 50 years of age seemed to have a significantly higher chance of developing post-treatment disease. Presumably, the healing process in older patients is slower and not as effective due to physiological aging process [30]. The increased incidence of secondary or tertiary dentine deposition, pulp stones, and internal/dystrophic calcification with age could result in canal obliteration, posing a challenge to optimal root canal preparation with a negative effect on healing outcome. The finding of a lower chance of tooth survival for older individuals corroborated with that of other studies [31, 32].

Some systematic reviews have concluded that while tooth type does not affect the periapical healing after primary root canal treatment [33], molar teeth were associated with a lower chance of survival [4]. Our results, indeed, showed that molars were associated with the greatest risk (or highest hazard ratio) of developing post-treatment disease and fared the shortest tooth survival time. This may be attributable to the complex anatomy of molars, accessibility and technical difficulties in treating them, as well as to heavy occlusal stresses acting on these teeth [34]. It should be mentioned that the unit of measurement was the tooth, not root, in the present study. The status of a multi-rooted tooth was represented by the worst-appearing root and, thus, molars would have multiple chances for post-treatment disease, compared with singlerooted teeth. Another situation may exist; for instance, the root with a grossly overextended root filling might not be the root associated with the largest periapical rarefaction. In other words, confounding of the true effect of a factor may exist for post-treatment disease for multi-rooted teeth.

A periapical lesion tends to develop more or less concentrically around the root apex with the apical foramen acting as the "source" of irritation that is situated in the center of the (radiographic) lesion. Some authors refer the apical foramen as the "portal of exit" for irritants to escape into the apical periodontium $[35,36]$. Although an attempt was made to quantify the size of radiographic lesions, in this study, the vertical (length-wise) dimension was not considered as it may be constrained by anatomic borders, such as the maxillary sinus or mandibular canal. The vertical angulation of the X-ray beam is also more likely to vary, compared with the horizontal angulation, when a film-holder is in use. Teeth with a pre-operative lesion especially those with a transverse diameter greater than $5 \mathrm{~mm}$ had the highest odd to fail (i.e., high hazard ratio) in either outcome measure. The result was consistent with that of studies carried out in other countries [11, 16, 37]. This reflects the difficulties in effective disinfection of the root canal system of teeth with an established infection [36]. No significant difference was found between lesions of size greater or smaller than $5 \mathrm{~mm}$ in diameter. As healing is a function of time, an outcome similar to smaller-sized lesions should be applicable to larger-sized lesions, if sufficient time was allowed for healing to take place [37].

This study reiterated the importance of homogenous root canal fillings (absence of apparent voids) [16] and the 
extension within $2 \mathrm{~mm}$ of the radiographic apex (or "flush") for optimal periapical healing $[10,11,16,37]$. Both results were confirmed by a recent systematic review [33]. However, these two factors did not seem to affect tooth survival. Although root fillings of insufficient quality in terms of length and seal should increase the risk of tooth loss due to the development of apical periodontitis, neither the quality of root filling nor the presence of apical periodontitis is easily noticeable by the patient [38]. In the absence of clinical symptoms, the treatment need may not be translated into demand.

Root canal-treated teeth opposing the natural tooth/teeth were consistently found to be associated with a significantly lower survival rate for both outcome measures, when compared to those opposing a denture, fixed prosthesis, or without any opposing dentition. It might be related to the damaging effects of premature contacts or occlusal stresses during function. This might translate into an increased risk of tooth fracture, leading to a need for tooth extraction. It has been suggested that occlusal trauma was associated with increased chance of unfavorable periapical healing [39].

The presence of cuspal coverage restorations was associated with an increased chance of periapical healing and of tooth survival, a finding supported by numerous other studies $[10,11,24,34,40-42]$ as well as systematic reviews $[4,43]$. The importance of cuspal protection for root canaltreated teeth to prevent cuspal flexure cannot be overemphasized. Without such protection, the (micro-)flexure may lead to breakdown of the marginal seal of simple intracoronal restoration and result in (coronal-to-apical) microleakage which hampers periapical healing [44]. Tooth fracture is also prevented, especially for molars which were the tooth type associated with the least favorable outcomes in this study. Aquilino and Caplan [34] have reported that root canal-treated teeth without a crown suffered six times greater rate of tooth loss than those with one.

Exposure of the root canal filling to saliva and bacteria is a serious challenge to the seal provided by the obturation material $[45,46]$. A good-quality coronal restoration is important to ensure long-term success of root canal treatment $[47,48]$. Indeed, the result of this study indicated that teeth presented with unsatisfactory tooth/restoration margin (due to marginal defects, fractures, or recurrent caries) would suffer from a less favorable outcome than those with satisfactory margins.

The number of visits to complete the treatment did not affect the periapical healing, but a lower number was associated with more favorable tooth survival compared to those completed in four or more visits. Protracted treatment may be a reflection of increased technical difficulties or problems in treatment, hence reducing the chance for survival or healing. Apical periodontitis would resolve upon thorough disinfection and elimination of microorganisms from the infected root canal system [49], regardless of the number of treatment visits.

\section{Conclusions}

For both periapical healing and tooth survival after primary root canal treatment, the survival curves declined in a nonlinear pattern, showing a steep drop up to about 40 months which then slowed down over longer observation periods. The median time of tooth survival (approximately 252 months) was considerably greater than those without post-treatment disease (approximately 119 months). Persistence or progression of periapical periodontitis was the most prevalent reason for adverse treatment outcomes. Age, tooth type, pre-operative periapical status, occlusion, type of final restoration, and the quality of tooth/restoration margin significantly affected the long-term periapical healing and tooth survival. The apical extent and homogeneity of the root canal fillings only contributed significantly towards periapical healing, but did not seem to affect survival of the treated teeth.

Acknowledgment The authors would like to thank Ms. K.Y. Cheung for her kind assistance in performing the statistical analysis.

Conflict of interest The authors declare that they have no conflict of interest.

Open Access This article is distributed under the terms of the Creative Commons Attribution Noncommercial License which permits any noncommercial use, distribution, and reproduction in any medium, provided the original author(s) and source are credited.

\section{References}

1. European Society of Endodontology (2006) Quality guidelines for endodontic treatment: consensus report of the European Society of Endodontology. Int Endod J 39:921-930

2. Friedman S, Mor C (2004) The success of endodontic therapyhealing and functionality. J Can Dent Assoc 32:493-503

3. Iqbal M, Kim S (2007) For teeth requiring endodontic treatment, what are the differences in outcomes of restored endodontically treated teeth compared to implant-supported restorations? Int $\mathrm{J}$ Oral Maxillofac Implants 22:96-116

4. Ng Y-L, Mann V, Gulabivala K (2010) Tooth survival following non-surgical root canal treatment: a systematic review of the literature. Int Endod J 43:171-189

5. Weiger R, Axmann-Krcmar D, Löst C (1998) Prognosis of conventional root canal treatment reconsidered. Endod Dent Traumatol 14:1-9

6. Cheung GSP (2002) Survival of first-time nonsurgical root canal treatment performed in a dental teaching hospital. Oral Surg Oral Med Oral Pathol Oral Radiol Endod 93:596-604

7. Davies JA (1987) Dental restoration longevity: a critique of the life table method of analysis. Community Dent Oral Epidemiol 15:202-204 
8. Sasieni PD (2005) Survival analysis. In: Handbook of epidemiology. Springer, Berlin, pp 693-728

9. Lesaffre E, Komárek A, Declerk D (2005) An overview of methods for interval-censored data with an emphasis on application in dentistry. Stat Methods Med Res 14:539-552

10. Cheung GSP, Chan TK (2003) Long-term survival of primary root canal treatment carried out in a dental teaching hospital. Int Endod J 36:117-128

11. Dammaschke T, Steven D, Kaup M, Reiner KH (2003) Long-term survival of root canal treated teeth: a retrospective study over 10 years. J Endod 29:638-643

12. Lindsey JC, Ryan LM (1998) Tutorial in biostatistics. Method for interval-censored data. Stat Med 17:219-238

13. Zhang Z, Sun J (2010) Interval censoring. Stat Methods Med Res 19:53-70

14. Molven O, Halse A, Fristad I (2002) Long-term reliability and observer comparisons in the radiographic diagnosis of periapical disease. Int Endod J 35:142-147

15. Strindberg LZ (1956) The dependence of the results of pulp therapy on certain factors. An analytical study based on radiographic and clinical follow-up examination. Acta Odontol Scand 14:1-174

16. Stoll R, Betke K, Stachniss V (2005) The influence of different factors on the survival of root canal fillings: a 10-year retrospective study. J Endod 31:783-790

17. SAS Institute Inc (2008) SAS/STAT ${ }^{\circledR} 9.2$ user's guide. SAS Institute Inc, Cary, NC, pp 3018-3019

18. Daya S (2005) Life table (survival) analysis to generate cumulative pregnancy rates in assisted reproduction: are we overestimating our success rates? Hum Reprod 20:1135-1143

19. Huumonen S, Ørstavik D (2002) Radiological aspects of apical periodontitis. Endod Top 1:3-25

20. Bender IB, Seltzer S (1961) Roentgenographic and direct observation of experimental lesions in bone: II. J Am Dent Assoc 62:152-160

21. Lee S-J, Messer HH (1986) Radiographic appearance of artificially prepared periapical lesions confined to cancellous bone. Int Endod J 19:64-72

22. Barbat J, Messer HH (1998) Detectability of artificial periapical lesions using direct digital and conventional radiography. J Endod $24: 837-842$

23. Garcia de Paula-Silva FM, Wu M-K, Leornado MR, Bezerra da Silva LA, Wesselink PR (2009) Accuracy of periapical radiography and cone-beam computed tomography scans in diagnosing apical periodontitis using histopathological findings as a gold standard. J Endod 35:1009-1012

24. Salehrabi R, Rotstein I (2004) Endodontic treatment outcomes in a large patient population in the USA: an epidemiological study. J Endod 30:846-850

25. Lazarski MP, Walker WA, Flores CM, Schindler WG, Hargreaves KM (2001) Epidemiological evaluation of the outcomes of nonsurgical root canal treatment in a large cohort of insured dental patients. J Endod 27:791-796

26. Chen S-C, Chueh L-H, Hsiao CK, Tsai M-Y, Ho S-C, Chiang C-P (2007) An epidemiology study of tooth retention after nonsurgical endodontic treatment in a large population in Taiwan. J Endod 33:226-229

27. Kerekes K, Tronstad L (1979) Long-term results of endodontic treatment performed with a standardized technique. J Endod 5:83-90

28. Hoskinson SE, Ng Y-L, Hoskinson AE, Moles DR, Gulabivala K (2002) A retrospective comparison of outcome of root canal treatment using two different protocols. Oral Surg Oral Med Oral Pathol Oral Radiol Endod 93:705-715

29. de Chevigny C, Dao TT, Basrani BR, Marquis V, Farzaneh M, Abitbol S, Friedman S (2008) Treatment outcome in endodontics: the Toronto study. Phase 4: initial treatment. J Endod 34:258-263

30. Ørstavik D, Qvist V, Stoltze K (2004) A multivariate analysis of the outcome of endodontic treatment. Eur J Oral Sci 112:224-230

31. Caplan DJ, Weintraub JA (1997) Factors related to loss of root canal filled teeth. J Public Health Dent 57:31-39

32. Mindiola MJ, Mickel AK, Sami C, Jones JJ, Lalumandier JA, Nelson SS (2006) Endodontic treatment in an American Indian population: a 10-year retrospective study. J Endod 32:828-832

33. Ng Y-L, Mann V, Rahbaran S, Lewsey J, Gulabivala K (2008) Outcome of primary root canal treatment: systematic review of the literature. Part 2: influence of clinical factors. Int Endod J 41:6-31

34. Aquilino SA, Caplan DJ (2002) Relationship between crown placement and the survival of endodontically treated teeth. J Prosthet Dent 87:256-263

35. Nair PNR (1987) Light and electron microscopic studies of root canal flora and periapical lesions. J Endod 13(1):29-39

36. Friedman S (2008) Expected outcome in the prevention and treatment of apical periodontitis. In: Orstavik D, Pitt Ford TR (eds) Essential endodontology, 2nd edn. Blackwell Science, Oxford, UK, pp 408-469

37. Sjögren U, Hägglund B, Sundqvist G, Wing K (1990) Factors affecting the long-term results of endodontic treatment. J Endod $16: 498-504$

38. Eckerbom M, Magnusson T, Martinsson T (1992) Reasons for and incidence of tooth mortality in a Swedish population. Endod Dent Traumatol 8:230-234

39. Matsumoto T, Nagai T, Ida K, Kawai Y, Horiba N, Sato R, Nakamura H (1987) Factors affecting successful prognosis of root canal treatment. J Endod 13:239-242

40. Meeuwissen R, Eschen S (1983) Twenty years of endodontic treatment. J Endod 9:390-393

41. Vire DE (1991) Failure of endodontically treated teeth: classification and evaluation. J Endod 17:338-342

42. Caplan DJ, Kolker J, Rivera EM, Walton RE (2002) Relationship between number of proximal contacts and survival of root canal treated teeth. Int Endod J 35:193-199

43. Stavropoulou AF, Koidis PT (2007) A systematic review of single crowns on endodontically treated teeth. J Dent 35:761-767

44. Saunders WP, Saunders EM (1994) Coronal leakage as a cause of failure in root canal therapy. A review. Endod Dent Traumatol 10:105-108

45. Madison S, Wilcox LR (1988) An evaluation of coronal microleakage in endodontically treated teeth. Part III. In vivo study. J Endod 14:455-458

46. Torabinejad M, Ung B, Kettering JD (1990) In vitro bacterial penetration of coronally unsealed endodontically treated teeth. J Endod 16:566-569

47. Hommez GMG, Coppene CRM, De Moor RJG (2002) Periapical health related to the quality of coronal restorations and root fillings. Int Endod J 35:680-689

48. Kqyahan MB, Malkondu O, Canpolat C, Kaptan F, Byirili G, Kazazoglu E (2008) Periapical health related to the type of coronal restorations and quality of root canal fillings in a Turkish subpopulation. Oral Surg Oral Med Oral Pathol Oral Radiol Endod 103:e58-e62

49. Sjögren U, Figdor D, Persson S, Sundqvist G (1997) Influence of infection at the time of root filling on the outcome of endodontic treatment of teeth with apical periodontitis. Int Endod J 30:297-306 